\title{
Is Workstyle a Mediating Factor for Pain in the Upper Extremity Over Time?
}

\author{
Eline M. Meijer · Judith K. Sluiter • \\ Monique H. W. Frings-Dresen
}

Published online: 8 August 2008

(C) The Author(s) 2008. This article is published with open access at Springerlink.com

\begin{abstract}
Introduction Upper extremity musculoskeletal disorders influence workers' quality of life. Workstyle may be one factor to deal with in workers with pain in the upper extremity. The objective of this study was to determine if workstyle is a mediating factor for upper extremity pain in a changing work environment of office workers over time. Methods Office workers with upper extremity pain filled out a Workstyle questionnaire (WSF) at baseline $(n=110)$. After 8 and 12 months follow-up assessment took place. Participants were divided into a good and an adverse workstyle group at baseline. The presence of upper extremity pain in both groups was calculated and relative risks were determined. Chi-square tests were used. Results Eight months after baseline, $80 \%$ of the adverse and $45 \%$ of the good workstyle group reported pain. The relative risk (RR) of having upper extremity pain for the adverse compared to the good workstyle group was 1.8 (95\% CI 1.08-2.86) $(P=0.055)$. Twelve months after baseline, upper extremity pain was more often presented in the adverse workstyle compared to the good workstyle group $(\mathrm{RR}=3.0, \quad(95 \%$ CI 1.76-5.11),$P=0.003)$. Twelve months after baseline, $100 \%$ of the adverse workstyle group and $33 \%$ of the good workstyle group reported pain in the upper extremity. Conclusion Workstyle seems to be a mediating factor for upper extremity pain in office workers in a changing work environment. It is recommended to assess workstyle among office workers with upper extremity pain, and to include workstyle behaviour in treatments.
\end{abstract}

E. M. Meijer · J. K. Sluiter $(\bowtie) \cdot$ M. H. W. Frings-Dresen Coronel Institute of Occupational Health, Academic Medical Center, University of Amsterdam, P.O. Box 22700,

1100 DE Amsterdam, The Netherlands

e-mail: j.sluiter@amc.nl
Keywords UEMSD - Upper extremity pain · Workstyle · Questionnaires-Psychometrics

\section{Introduction}

High prevalence and incidence rates for work-related musculoskeletal disorders of the upper extremity (UEMSDs) have been reported for office workers [1-3]. Several sociodemographic factors have been shown to be a risk factor for developing UEMSDs [1, 4-12]. Furthermore, exposure to some physical work demands and some psychosocial work characteristic can be risk factors for the onset of UEMSDs [13-18] as well.

However, when office workers have developed pain in their upper extremity, other factors become important to deal with; workstyle might be such a factor [19]. The concept workstyle, introduced by Feuerstein and colleagues, is defined as "a behavioural, cognitive and physiological response that can occur in individuals to increases in work demands" [20, 21]. Adverse workstyle may be self-generated by experienced time pressure, a high need for acceptance and achievement or fear of negative consequences [22].

Workstyle seems to be a mediating factor in the relation between job demands and pain in the upper extremity. Moreover, adverse workstyle seems to be predictive of future upper extremity pain and functional limitations among office workers [23]. In a study to determine the role of workstyle in UEMSD, it was shown that workers with pain had significantly more frequent unfavourable workstyle scores than workers without pain [24]. However, due to the cross-sectional design of this study [24] and the lack of other, high quality, studies on behavioural factors, results seem promising but are too scarce to draw conclusions [19]. It seems interesting to study if workstyle is a 
mediating factor for upper extremity pain for office workers when considered over time.

In this present study, a longitudinal study was performed in an office building of a Dutch governmental institute. In order to increase communication and cooperation between employees, the office building was totally renovated from traditional cellular workplaces to a shared open-plan office, and the new office aimed to be paperless. The implementation of this innovative office concept results in a totally new situation at the workplace. A new situation at the workplace can be considered as an temporarily increase in the job demands [25, 26]. Increased job demands is assumed because of the significant change workers have to deal with employing the different workstyle.

The objective of this study was to determine the mediating effect of workstyle on upper extremity pain in office workers. Because of the high impact of having an UEMSD on workers' quality of life [27], it is important to be able to identify people at high risk for developing or maintaining UEMSDs within a working population. It was hypothesised that in workers with pain in the upper extremity, specifically pain in the upper extremity after 8 or 12 months is more prevalent in workers with an adverse workstyle compared to office workers with a good workstyle. The following research question was formulated: Is workstyle a mediating factor for pain in the upper extremity in office workers in a changing work environment over time?

\section{Methods}

\section{Measurements}

Three measurements were performed over time. The first measurement (baseline) was performed in March 2006. Because this study was part of another study (www. trialregister.nl ISRCTN 13222474), the second measurement (T2) was performed 8 months later. The third measurement (T3) took place 12 months after baseline. All measurements were assessed by digital questionnaires.

\section{Workstyle}

Workstyle was determined with the Workstyle Short Form (WSF) [20, 21]. The WSF contains 32 items within eight subscales. Part 1 of the WSF consisted of six subscales (working through pain, social reactivity, limited workplace support, deadlines/pressure, self-imposed workpace/workload, and breaks) using 5-point response scales, ranging from 0 (almost never) to 4 (almost always). Part 2 of the WSF consisted of two subscales (mood and autonomic response) of dichotomous response categories. The total workstyle score was calculated by summing the sum scores of part 1 and part 2 and could range between -8 and 95 . A workstyle score was considered at risk if the total score was 28 or higher [21].

Population

Office workers were selected from a population of office workers who were voluntarily participating in another study (www.trialregister.nl ISRCTN 13222474). In that study, office workers were included when they were working on a desktop computer for at least 2 days a week, for more than $4 \mathrm{~h}$ per day. For this current study, participants were selected out of that population, who reported pain in the upper extremity at baseline $(n=120,51$ men and 69 female). The mean age was 45 years (SD 9.3) and they worked on average $31 \mathrm{~h}$ per week (SD 6.6).

The selected study population was divided into a group of workers with a good workstyle and a group with an adverse workstyle at baseline, using the cut-off score of 28 [21]: The good workstyle group included workers with a total WSF score of 27 or less at baseline and at follow up (after 8 or 12 months). The adverse workstyle group consisted of workers with a total WSF score of 28 or higher at baseline and at follow up.

\section{Outcome}

Pain in the upper extremity was the outcome variable of this study. Both at baseline and at follow-up, participants were asked to put a cross on a Visual Analogue Scale (VAS $=0$ to 100 ) that best represented their pain in the last $24 \mathrm{~h}$. Pain in the upper extremity was defined as having a pain score above 0 measured on a VAS, a score of 0 on the VAS was defined as having no pain.

\section{Analyses}

Three groups of office workers were analysed: (1) The group of office workers with pain at baseline, who had filled out the pain question after 8 months and showed a steady workstyle over this time period (T2); (2) the group of office workers with pain at baseline who had filled out the pain question after 12 months (T3) and showed a steady workstyle over this time period; and (3) the population with pain at baseline who filled out the pain question at both T2 and T3 and did not change workstyle over time. A steady workstyle was defined as having a consistent workstyle score between the time periods that were analysed (e.g., an adverse workstyle at baseline and T2 for analysis [1]).

To determine if there were differences between the adverse workstyle group and the good workstyle group of office workers with pain in the upper extremity at follow up 
over time, relative risks (RR) and (95\% confidence interval) were calculated between the groups and Chi-square tests were used to test the RR between the workstyle groups at follow up. To give readers more insight, the mean level of pain per group is presented per measurement. Furthermore, differences between the adverse workstyle group and the good workstyle group at baseline were tested with $t$-tests. For all analyses, significant difference was defined as $P<0.05$.

\section{Results}

\section{Participants}

Of the total study population ( $n=120), 110$ office workers filled out the workstyle questionnaire at baseline. A adaptive workstyle was reported in 77 office workers (70\%) and 33 office workers (30\%) had an adverse workstyle. A total of 43 participants had filled out the pain question after 8 months and showed a steady workstyle over time and could therefore be used for analyses after 8 months (at T2). Of these, 10 had an adverse workstyle and 33 workers had a good workstyle at both time points. At baseline, the mean level of pain in the adverse workstyle group was 49. In the good workstyle group, the baseline pain level was 32 . This difference was statistically significant $(P=0.039)$. A total of 33 participants had filled out the pain question after 12 months, had a steady workstyle over this time period and could therefore be used for analyses over the 12 month peroid (at T3). A good workstyle over time was found in 27 workers (mean pain level at baseline: 51) and six workers were defined as having an adverse workstyle (mean pain at baseline: $30, P=0.053$ ). Only six workers were available for the analyses on all measurements, all of whom reported an adverse workstyle.

\section{Risk of Pain at Follow Up}

The RR of having upper extremity pain 8 months after baseline for the adverse workstyle group compared to the good workstyle group was RR 1.8 (95\% CI 1.08-2.86) $(P=0.055)$. Eight months after baseline, $80 \%$ of the workers in the adverse workstyle group and $45 \%$ of the workers in the good workstyle group reported pain in the upper extremity at the time of T2. See Table 1 for the number of office workers who reported pain in the upper extremity at $\mathrm{T} 2$ in the adverse and good workstyle group.

Twelve months after baseline, there was a significant difference in the presence of upper extremity pain between the workstyle groups $(P=0.003)$. The $\mathrm{RR}$ of having pain at T3 for the adverse workstyle group compared to the good work group was RR 3.0 (95\% CI 1.76-5.11). Twelve
Table 1 Number of office workers with upper extremity pain and without pain, 8 months after baseline in the group of workers with an adverse workstyle and in the group with a good workstyle

\begin{tabular}{lccl}
\hline & Pain & No pain & Total $(n)$ \\
\hline Adverse workstyle group & 8 & 2 & 10 \\
Good workstyle group & 15 & 18 & 33 \\
Total $(n)$ & 23 & 20 & 43 \\
\hline
\end{tabular}

Table 2 Number of office workers with upper extremity pain and without pain, in the adverse workstyle group and in the good workstyle group, 12 months after baseline

\begin{tabular}{lccc}
\hline & Pain & No pain & Total $(n)$ \\
\hline Adverse workstyle group & 6 & 0 & 6 \\
Good workstyle group & 9 & 18 & 27 \\
Total $(n)$ & 15 & 18 & 33 \\
\hline
\end{tabular}

months after baseline, $100 \%$ of the adverse workstyle group and $33 \%$ of the good workstyle group reported pain in the upper extremity. Table 2 summarises the number of upper extremity pain cases after 12 months (T3) for the adverse and good workstyle group.

As mentioned above (see section "Participants"), in the population that filled out both the pain question and the workstyle questionnaire at baseline and after eight months (T2) $(n=43)$, only six office workers filled out the pain question after 12 months (T3) and did not change from workstyle type. All six office workers reported pain at T3 and scores in the adverse workstyle; range a good workstyle or having no pain was not reported. Because of these low numbers, no RR or tests were performed.

\section{Discussion}

In this study, the mediating effect of workstyle on upper extremity pain in office workers has been evaluated. The results show that an adverse workstyle is a mediating factor for pain in the upper extremity in office workers in the long term (12 months). Office workers with an adverse workstyle have a three times higher risk of pain after 12 months compared to office workers with a good workstyle. Furthermore, a trend can be seen in the mediating effect of workstyle 8 months after baseline. After 8 months, office workers with an adverse workstyle had a relative risk of 1.8 of pain in the upper extremity compared to office workers with a good workstyle.

The hypothesis tested of whether workstyle was a mediating factor for pain in the upper extremity over time in a changing work environment, is largely confirmed in 
this study. However, the difference in risk of having pain in the upper extremity after 8 months is not statistical significant between the adverse and good workstyle group. This may be explained by the relative small number of workers in this study. The baseline risk for experiencing upper extremity pain was $53 \%$ in our population. The 1.8 times higher risk in workers with an adverse workstyle after 8 months (see Table 2) is, therefore, thought to be a very relevant outcome. Furthermore, the baseline level of pain in the adverse workstyle group was higher than in the adaptive workstyle group $(P=0.038$ vs $P=0.053)$. This may be a mediating factor for pain in office workers itself. However, on the contrary, workstyle may also affect the level of pain of the workers. It would be interesting to study the level of pain in future research on workstyle.

This study showed that an adverse workstyle increases the risk of having upper extremity pain in office workers. This finding assumes that assessing workstyle among office workers who have pain in the upper extremity might be indicated. By identifying workers with upper extremity pain with an adverse workstyle, changing workstyle behaviour would be appropriate in rehabilitation activities. Because workstyle is a combination of factors, such as working through pain, deadlines/pressure, and selfimposed workload that contribute to upper extremity pain, interventions could be developed to address each of these contributing factors to adverse workstyle [23].

In a recently published randomized controlled trial, an intervention was evaluated that aimed at changing office workers' workstyle [28-30]. In short, the workstyle intervention consisted of six sessions within a 6 months period. Information was provided about upper extremity pain and the risk factors body posture, static workload, insufficient breaks, high workload and work stress. Furthermore, guidelines for workplace adjustments were provided and these adjustments were checked in practice. Using work breaks was stimulated and how to recognize work stress was discussed. General and individual risk factors for work stress, and different ways of coping with work stress were discussed, and solutions for these risk factors were searched for [30]. This workstyle intervention was only effective in reducing pain outcomes of the neck/shoulder symptoms in the long term (after 12 months of follow up), while no effects on arm/wrist/hand pain in the short-term (i.e. after 6 months of follow-up) were found [28]. Therefore, the content or implementation strategies of workstyle interventions need more study. Refining workstyle interventions by including bio-behavioural factors, such as working through pain, that influence arm and hand pain, may be a promising alternative [31].

Van den Heuvel et al. [24] studied the mediating effect of workstyle in the relationship between work exposure and upper extremity pain. The subscales 'working through pain' and 'social reactivity' had the largest mediating effects [24]. This is in accordance with the current study results that show that the subscale working through pain attributes most of all subscales to the total workstyle score [both mean 10.26 (SD 4.9) and median score: 11.00]. However, in the study of van den Heuvel [24], only half of the subscale working through pain was assessed. Therefore, scores are not comparable between the two studies. In our study, we used the authorized Dutch translation of all 32 items of the workstyle short form measure as was described by Feuerstein and Nicholas [21]. Furthermore, contrary to results of van den Heuvel et al. [24], social reactivity did not contribute substantially to the total workstyle score in this study, with a mean score at baseline of 2.2 (median $=0$ ). Therefore, it may be assumed that refining workstyle interventions by changing working through pain behaviour may be promising.

Some remarks can be made about the choice of the population used in this study. Only office workers showing a steady workstyle over time (between baseline and follow up) were included in the analysis. One reason for this choice was the availability of the data. Furthermore, as a result of this, it has been possible to look at workstyle as a factor over time that may explain why some office workers had pain and other workers had no pain after the same increase in work demands (i.e. the changes in working environment due to the implementation of the new office concept). It was assumed that if a mediating effect of workstyle exists, it could be found most easily within this steady workstyle group. However, this conclusion should be drawn with some care, because only about one-third (33 out of the 110) of the office workers with pain at baseline showed a steady workstyle over the 12 months follow up period and filled out the questionnaire and were therefore included in the analysis. Furthermore, the studied population comprised mainly highly educated office workers (60\% had a bachelor's or master's degree). Feuerstein and Nicholas [21] also reported on a population of highly educated workers, when determining the correlation between workstyle and upper extremity pain. In order to generalize to the general workforce, it is recommended that a study be conducted to address workstyle issues in workers with lower levels of education who are experiencing increased job demands [21].

In conclusion, workstyle seems to be a mediating factor for upper extremity pain in office workers within a changing work environment in the long term. This study could be seen as providing additional preliminary data on the construct. It is recommended to assess workstyle among office workers who have pain in the upper extremity, and to include changing workstyle behaviour into the treatment of office workers with these complaints. 
Open Access This article is distributed under the terms of the Creative Commons Attribution Noncommercial License which permits any noncommercial use, distribution, and reproduction in any medium, provided the original author(s) and source are credited.

\section{References}

1. Gerr F, Marcus M, Ensor C, Kleinbaum D, Cohen S, Edwards A, et al. A prospective study of computer users: I. Study design and incidence of musculoskeletal symptoms and disorders. Am J Ind Med. 2002;41:221-35. doi:10.1002/ajim.10066.

2. Heinrich J, Blatter BM. RSI-klachten in de Nederlandse beroepsbevolking. Trends, risicofactoren en verklaringen. TSG. 2005; 83:16-24.

3. de Kraker H, Blatter BM. Prevalentiecijfers van RSI-klachten en het vóórkomen van risicofactoren in 15 Europese landen. TSG. 2005;83:8-15.

4. Cassou B, Derriennic F, Monfort C, Norton J, Touranchet A. Chronic neck and shoulder pain, age, and working conditions: longitudinal results from a large random sample in France. Occup Environ Med. 2002;59:537-44. doi:10.1136/oem.59.8.537.

5. Marcus M, Gerr F, Monteilh C, Ortiz DJ, Gentry E, Cohen S, et al. A prospective study of computer users: II. Postural risk factors for musculoskeletal symptoms and disorders. Am J Ind Med. 2002;41:236-49. doi:10.1002/ajim.10067.

6. Jensen C, Finsen L, Sogaard K, Christensen H. Musculoskeletal symptoms and duration of computer and mouse use. Int $\mathrm{J}$ Ind Ergonom. 2002;30:265-75. doi:10.1016/S0169-8141(02)00130-0.

7. Jensen C. Development of neck and hand-wrist symptoms in relation to duration of computer use at work. Scand J Work Environ Health. 2003;29:197-205.

8. Korhonen T, Ketola R, Toivonen R, Luukkonen R, Hakkanen M, Viikari-Juntura E. Work related and individual predictors for incident neck pain among office employees working with video display units. Occup Environ Med. 2003;60:475-82. doi:10.1136/oem. 60.7.475.

9. Lassen CF, Mikkelsen S, Kryger AI, Brandt LP, Overgaard E, Thomsen JF, et al. Elbow and wrist/hand symptoms among 6,943 computer operators: a 1-year follow-up study (the NUDATA study). Am J Ind Med. 2004;46:521-33. doi:10.1002/ajim.20081.

10. Juul-Kristensen B, Jensen C. Self-reported workplace related ergonomic conditions as prognostic factors for musculoskeletal symptoms: the "BIT" follow up study on office workers. Occup Environ Med. 2005;62:188-94. doi:10.1136/oem.2004.013920.

11. Cole DC, Ibrahim S, Shannon HS. Predictors of work-related repetitive strain injuries in a population cohort. Am J Public Health. 2005;95:1233-7. doi:10.2105/AJPH.2004.048777.

12. Nahit ES, Hunt IM, Lunt M, Dunn G, Silman AJ, Macfarlane GJ. Effects of psychosocial and individual psychological factors on the onset of musculoskeletal pain: common and site-specific effects. Ann Rheum Dis. 2003;62:755-60. doi:10.1136/ard.62.8.755.

13. Bongers PM, Kremer AM, ter Laak J. Are psychosocial factors, risk factors for symptoms and signs of the shoulder, elbow, or hand/wrist?: a review of the epidemiological literature. Am J Ind Med. 2002;41:315-42. doi:10.1002/ajim.10050.

14. Devereux JJ, Vlachonikolis IG, Buckle PW. Epidemiological study to investigate potential interaction between physical and psychosocial factors at work that may increase the risk of symptoms of musculoskeletal disorder of the neck and upper limb. Occup Environ Med. 2002;59:269-77. doi:10.1136/oem.59.4.269.

15. Feuerstein M, Huang GD, Haufler AJ, Miller JK. Development of a screen for predicting clinical outcomes in patients with workrelated upper extremity disorders. JOEM. 2000;42:749-61.
16. Larsman P, Sandsjo L, Klipstein A, Vollenbroek-Hutten M, Christensen H. Perceived work demands, felt stress, and musculoskeletal neck/shoulder symptoms among elderly female computer users. The NEW study. Eur J Appl Physiol. 2006;96: 127-35. doi:10.1007/s00421-004-1263-6.

17. Macfarlane GJ, Hunt IM, Silman AJ. Role of mechanical and psychosocial factors in the onset of forearm pain: prospective population based study. Brit Med J (Clin Res Ed.). 2000;321: 676-9. doi:10.1136/bmj.321.7262.676.

18. Sluiter JK, Rest KM, Frings-Dresen MH. Criteria document for evaluating the work-relatedness of upper-extremity musculoskeletal disorders. Scand J Work Environ Health. 2001;27(Suppl 1): $1-102$.

19. Bongers PM, Ijmker S, van den Heuvel S, Blatter BM. Epidemiology of work related neck and upper limb problems: psychosocial and personal risk factors (Part I) and effective interventions from a bio behavioural perspective (Part II). J Occup Rehabil. 2006;16: 272-95. doi:10.1007/s10926-006-9044-1.

20. Feuerstein M, Nicholas RA, Huang GD, Haufler AJ, Pransky G, Robertson M. Workstyle: development of a measure of response to work in those with upper extremity pain. J Occup Rehabil. 2005;15:87-104. doi:10.1007/s10926-005-3420-0.

21. Feuerstein M, Nicholas RA. Development of a short form of the Workstyle measure. Occup Med-Oxford. 2006;56:94-9. doi: 10.1093/occmed/kqi197.

22. Feuerstein M. Workstyle: definition, empirical support, and implications for prevention, evaluation and rehabilitation of occupational upper-extremity disorders. In: Moon SD, Sauter SL, editors. Beyond biomechanics: psychosocial aspects of musculoskeletal disorders in office work. Bristol: Taylor and Francis Ltd.; 1996.

23. Nicholas RAM, Feuerstein MP, Suchday SP. Workstyle and upper-extremity symptoms: a biobehavioral perspective. JOEM. 2005;47:352-61.

24. van den Heuvel SG, van der Beek AJ, Blatter BM, Bongers PM. Workstyle and overcommitment in relation to neck and upper limb symptoms. Int J Behav Med. 2007;14:12-20.

25. Ursin H, Eriksen HR. The cognitive activation theory of stress. Psychoneuroendocrinology. 2004;29:567-92. doi:10.1016/S03064530(03)00091-X.

26. De Croon EM, Sluiter JK, Kuijer PP, Frings-Dresen MH. The effect of office concepts on worker health and performance: a systematic review of the literature. Ergonomics. 2005;48:119-34. doi:10.1080/00140130512331319409.

27. Sluiter JK, Frings-Dresen MH. Quality of life and illness perception in working and sick-listed chronic RSI patients. Int Arch Occup Environ Health. 2008;81:495-501. doi:10.1007/s00420007-0222-z.

28. Bernaards CM, Ariens GAM, Knol DL, Hildebrandt VH. The effectiveness of a work style intervention and a lifestyle physical activity intervention on the recovery from neck and upper limb symptoms in computer workers. Pain. 2007;132:142-53. doi: 10.1016/j.pain.2007.06.007.

29. Bernaards C, Ariens G, Simons M, Knol D, Hildebrandt V. Improving work style behavior in computer workers with neck and upper limb symptoms. J Occup Rehabil. 2008;18:87-101. doi:10.1007/s10926-007-9117-9.

30. Bernaards C, Ariens G, Hildebrandt V. The (cost-)effectiveness of a lifestyle physical activity intervention in addition to a work style intervention on the recovery from neck and upper limb symptoms in computer workers. BMC Musculoskelet Disord. 2006;7:80. doi:10.1186/1471-2474-7-80.

31. Feuerstein M. Workstyle: it's probably time we address both biomechanical and biobehavioral approaches? Pain. 2007;132:34. doi:10.1016/j.pain.2007.08.003. 